\title{
Life after Social Death: Leaving the Jehovah's Witnesses, Identity Transition and Recovery
}

\author{
Heather J. Ransom ${ }^{1}$ (D) $\cdot$ Rebecca L. Monk $^{1} \cdot$ Adam Qureshi $^{1} \cdot$ Derek Heim $^{1}$
}

Accepted: 23 November 2020/ Published online: 15 December 2020

(C) The Author(s) 2020

\begin{abstract}
It is well documented that religiosity is linked with positive indicators of well-being, but less research has examined the psychosocial impacts of leaving "high-control" religions. Theoretically situated in recovery and desistance literature underpinned by the social identity approach, the current study examined cross-sectionally the extent to which 'disfellowshipped' former Jehovah's Witnesses' experiences of ostracism and post-exit identification with others are associated with diminished psychological well-being and identity transition success. It also examined the extent to which the type of exit (forced vs. voluntary) and prior religious commitment shaped these outcomes. The authors recruited 554 adults $(62 \%$ female; $M$ age $=37.26$, SD age $=12.82)$ via online social support networks for former Jehovah's Witnesses. Path analysis tested the mediating and moderating functions of exit method (forced vs. voluntary), commitment level during membership, and post-exit group identification with groups on outcomes of identity transition, recovery identity, self-esteem, and well-being. Results indicate that individuals who voluntarily left the Jehovah's Witnesses reported more ostracism than those who were disfellowshipped (forced out) and that a higher level of prior religious commitment was associated with post-religious identity transition success and diminished self-esteem. Findings further suggest that distinct aspects of respondents' social identity were related differentially to outcomes in partial support of the theoretical framework. Future research and theory development efforts are deemed necessary to better understand the etiology of how exiting high-control religions impacts psychosocial outcomes.
\end{abstract}

Keywords Jehovah's witnesses · Ostracism · Identity · Self-esteem · Well-being · Religious exit

Religious affiliation can be associated with a range of psychological and social outcomes. Members of religious communities advocate that having a relationship with the divine impacts

Heather J. Ransom ransomh@edgehill.ac.uk

1 Department of Psychology, Edge Hill University, St Helens Road, Ormskirk, Lancashire L39 4QP, UK 
positively on self-esteem and can help to counteract negative life experiences such as ostracism (Aydin et al. 2010). Additionally, relationships with like-minded believers can bestow feelings of commonality (Pargament et al. 2000), and provide social support to members (Gebauer et al. 2012). Religiosity has also been described as a coping mechanism for individuals facing social isolation and loneliness (Ai et al. 2005; McIntosh et al. 1993), and is found to predict well-being (Park et al. 2018; Sherman et al. 2009). On the other hand, spirituality rather than religiosity per se has been linked to well-being and stress management (Jackson and Bergeman 2011). Similarly, other research indicates that religious membership may not always be beneficial for recovery from substance misuse and that spirituality may play a more prominent role (Kelly and Eddie 2020), with Alcoholics Anonymous (AA) having spirituality at the core of its recovery system (Alcoholics Anonymous 2001; Kelly 2017; Tonigan et al. 2013). In view of these somewhat mixed findings concerning benefits of religious membership and/or spirituality, it is also useful to examine what happens when membership is terminated as this can have a considerable influence on the lives of those affected.

Perhaps as a 'reciprocity fee' for benefits to members, throughout history religious groups have realized the influence they have over the lives of their followers towards maintaining unity and adherence to a given set of ideals (Miller 1988). By the same token, it is not uncommon for some religions to attempt to exert control over those who have left. Known as religious shunning, the complete withdrawal of social and spiritual contact with former believers may, for example, be used as a means of exerting a degree of control over leavers and of possibly motivating them to return to the fold (Gutgsell 2017; Holden 2002a, b). By now it has become apparent that religious shunning can be associated with an array of negative impacts (e.g., social, intellectual, legal, and logistical challenges) on the individuals involved (Berger 2015; Fazzino 2014; Gutgsell 2017; Iannaccone 1994). Thus, research documents that such practices can impact adversely the lives and life chances of leavers of high-control religions, including ultra-Orthodox Jews (Berger 2015), Muslims (Khalil and Bilici 2007), Mormons (Bahr and Albrecht 1989), evangelicals (Fazzino 2014), and Amish (Faulkner 2017). This body of work indicates that leaving comparatively strict religious groups can result in detrimental effects to the health and well-being of those affected (Faulkner 2017; Friedson 2015; Scheitle and Adamczyk 2010). Research in this domain, which has tended to be qualitative in nature, has therefore played an important role in giving a voice to those experiencing religious ostracism. It has also laid the groundwork for developing theoretical models of how both risk and protective factors may impact individuals' well-being, which can be tested in larger-scale samples. Towards this aim, the current study reports findings from a survey of former Jehovah's Witnesses.

Jehovah's Witnesses (JW) is a fundamentalist Christian religious organization established in the United States in 1879 by Charlies Taze Russell that is often classed as a new religious movement (Wilson and Cresswell 1999). JWs believe that humans are living in a time period that the Bible calls "the last days" and that the biblical war of Armageddon is imminent (Holden 2002b; Stark and Iannaccone 1997). Rejecting politics and all other religions (Holden 2002b), they class themselves as "no part of the world" (Wallis 1984). As such, although they are in the world, they do not consider themselves to be part of it, rejecting all religious holidays (e.g., Christmas), acts of patriotism, and unnecessary social interactions with nonbelievers. JWs are considered a "high-cost" religion mainly due to the consequences of exiting the faith (Scheitle and Adamczyk 2010). Specifically, although members gain a large social network of fellow believers, those exiting may be viewed as choosing to become part of the world and may be ostracized by family, friends, and the wider religious community who remain in the organization (Holden 2002b). Ostracism, in this way, is both used to reinforce 
"worldly distinctions" between JWs and non-JWs and acts as a deterrent against leaving. In considering the use of ostracism in high-control religions such as the JWs, it may be useful to examine how theoretical explanations of ostracism account for its deleterious effects.

Williams's (2009) temporal need-threat model (Williams 2009), for example, suggests that ostracism threatens four basic human needs: control, meaningful existence, self-esteem, and belonging. This three-stage model posits that responses and reactions to ostracism change over time, with an initial reflexive response of distress (Gonsalkorale and Williams 2007; van Beest and Williams 2006; Wesselmann and Williams 2017) and "social pain" (Ren et al. 2018; Wesselmann et al. 2012) leading to a second reflective stage that is seen to stimulate coping responses that serve to fortify threatened needs (e.g., control; Wesselmann and Williams 2017; Williams 2008; Zadro and Williams 2006). Finally, the third stage, resignation, is said to occur in the face of longer-term ostracism and can be associated with feelings of helplessness, alienation, despair, depression, and suicidal ideation (Williams 2009). By conceptualizing experiences of ostracism as a nonstatic process that may change alongside an individual's circumstances, this model appears well suited to help explain how religious ostracism develops over time as people leave. To date, however, the theory has primarily been tested under laboratory settings (e.g., using the cyberball paradigm; Hartgerink et al. 2015) and, as such, may not be generalizable to real-world contexts. Furthermore, the effects of longer-term ostracism are difficult to account for (ethically) under experimental settings. In view of the potentially harmful psychological effects of ostracism, a consideration of the leaving experiences of former JWs may therefore help cast light on real-world ostracism as well as its longer-term effects.

There are typically two routes of leaving the JW: (1) disfellowship (forced exit), the result of contravening religious rules, and (2) leaving the group voluntarily (known as disassociation or fading). Regardless of the exit route, former members often report being mandatorily shunned by their family and friends who remain in the faith (Holden 2002b; Hookway and Habibis 2015; Lalich and McLaren 2010; Ransom, Monk and Heim 2020; Testoni et al. 2019), and this can impact individuals in different ways. For example, in a study of former members who were born and raised as JWs before accepting that they were gay and subsequently found it impossible to reconcile their sexual and religious identities, respondents describe their religious exit as a distressing experience associated with self-destructive behavior, suicide, and suicidal ideation (Lalich and McLaren 2010). Similarly, Hookway and Habibis's (2015) in-depth study of former JWs raised in the organization details distressing accounts of disaffiliation as they transitioned out of the JW because of a perceived incompatibility between their desire for a more hedonistic lifestyle and the comparative asceticism of life in the JW. Other research specifically explores the effects of being disfellowshipped from the JW. Gutgsell's unpublished qualitative work (2017), for instance, details respondents' reactions to ostracism, which included decreased psychological well-being. Overall, this growing body of work highlights the potential harm to people's well-being as a result of experiencing ostracism. In these studies, respondents were either disfellowshipped or felt that they had little choice but to leave, providing an indication of the possibility that forced-choice exits may pose particular challenges to the well-being of individuals. Indeed, contrasting a forced exit with more voluntary forms of leaving may be an important consideration when seeking to understand the psychological and social impacts of leaving the JW. In support of this notion, a qualitative examination of the exit stories of those who had left the JW voluntarily found that although a measure of distress was experienced, those exiting tended to describe leaving the JW as a positive, life-affirming experience and as a way of building an authentic identity (Testoni et al. 2019). This may indicate that religious exit is not necessarily a linear process and that different factors may mitigate individual experiences. As such, findings of previous 
studies converge to provide a preliminary indication that those who leave of their own accord may find navigating life outside the organization easier than those who are disfellowshipped.

In addition to the possibility that mode of exit may impact leaving outcomes, research into leaving other religions highlights that the effects of exiting may differ as a function of motives for disaffiliation. In research examining characteristics that best describe motivations for deconversion, denial and disagreement with beliefs, moral criticism, emotional suffering, loss of religious experience, and religious community are suggested as reasons for departure (Streib et al. 2009), with most "deconverts" choosing a secularizing exit. A study examining defection from the Mormons (Bahr and Albrecht 1989), for example, documents how the desire for perceived freedom could serve as a strong motivation for exiting. In this study, respondents often reported knowing comparatively little about their religion and rejected what they perceived as a strict lifestyle. Describing themselves as not being "real Mormons," respondents identified a tension between what they viewed as an enforced lifestyle and the one they desired. These findings align with those by Davidman and Greil (2007; see also Davidman 2014), who found similar results among former ultra-Orthodox Jews while also documenting themes of uncertainty, fear, and loneliness upon their entering the secular world (see also BarLev and Shaffir 1997). Similarly, a recent Israeli study (Itzhaki et al. 2020) exploring ultraOrthodox Jewish high school dropouts found that becoming less religious was associated with reduced psychological well-being. In this study, youths reported experiencing a reduction in parental love because of their unwillingness to comply with religious norms.

Studies of people exiting evangelical movements, in contrast, have yielded divergent findings with regard to how motives and commitment to religions may intertwine to shape exiting. On the one hand, a study in the United States found that motivations for leaving included failure to retain commitment to a belief system, with respondents wanting to pursue what they regarded as a more authentic life (Fazzino 2014). On the other hand, research among leavers of an evangelical community in the United States found that participants expressed a desire to embark on a new faith journey and to pursue a different type of religious lifestyle (Jamieson 2002). Finally, an exploratory study regarding conversions out of Islam that included an examination of websites run by Christian missionaries and former Muslims identified intellectual/ideological motivations and social/experiential motives, respectively, for disaffiliation as well as different conversion destinations such as atheism, Christianity, and agnosticism (Khalil and Bilici 2007). These studies begin to paint a picture of the motivations people have for leaving a religion and may partly reflect initial levels of religious commitment. Together, these studies' findings may suggest that post-religious exit paths are shaped by and can differ substantially as a result of differing motivations regarding religious exiting. More specifically, although not empirically examined to date beyond these formative qualitative studies, existing research highlights the possibility that the initial commitment to religion of those who leave could also shape psychosocial outcomes post exit.

In addition to the apparent associations between leaving outcomes and form of exit (e.g., voluntary), religious commitment, and motivations for exiting, research also documents that loss of group membership may also be associated with psychosocial difficulties. Loss of social support can also be associated with threats to identity. For example, individuals who exit the Mormon (Joseph et al. 2017) and the ultra-Orthodox Jewish (Davidman and Greil 2007) faiths may struggle to reconcile their post-religious personal identity with that of their former religious culture. In this way, individuals may attempt to build a new identity by searching for social support from diverse people such as nonreligious relatives, online support groups, or counselors (Berger 2015). Similarly, exploration among ostracized former Amish (Faulkner 
2017) and ultra-Orthodox Jews (Davidman and Greil 2007) suggests that individuals exiting can experience difficulty abandoning their religious identity, resulting in a "holdover identity." Although holdover identities have not been the subject of exploration among former JWs, this work into other religions (see also work on "role exit" by Ebaugh 1988) provides an indication that threatened identities may be associated with religious exit and ostracism and may, therefore, be relevant when considering impacts of transitioning out of the JW organization. Indeed, one study in the ex-JW community describes losing relationships as "social mourning" (Testoni et al. 2019). On the other hand, Fazzino (2014) suggests that although leaving a highcontrol (evangelical) group can present psychosocial challenges initially, with loneliness as a motivation to find new social ties, deconversion is viewed as a liberating experience leading to relief and happiness. This suggests that, for some at least, time may act as a healing influence on recovery from social losses.

Considering the apparent significant role of social ties in these studies, it is conceivable that the advantages of religious membership may be accounted for theoretically by tenets of the social identity approach (Brown 2020; Tajfel 1978; Tajfel and Turner 1979). This perspective suggests that ties with like-minded individuals can create a sense of belonging (Levine et al. 2002; Swann et al. 2010, 2012; Turner and Hogg 1987) vis-à-vis the alignment of personal identity with that of the group to create a visceral sense of fused identity that can survive an exit from a group (Swann et al. 2010, 2012). Although not applied to religious exit to date, a growing body of work also documents the extent to which social identification can aid mental health outcomes (Haslam et al. 2011). It is therefore necessary to examine how identity processes impact individuals leaving high-control religious organizations such as the JWs.

Applying the social identity approach to explorations of leaving high-control religions may, in this way, be aided by considerations of theoretical insights derived from the desistance from crime and substance abuse literature (Best et al. 2017). Recovery, from this perspective, can be conceptualized as a process of identity transition in which individuals reorient towards groups impacting positively on their journey towards improvement (Best et al. 2016; Kay and Monaghan 2019). This transferring of group identity in the substance use literature, for example, is suggested to increase the likelihood of recovery while decreasing the likelihood of a relapse (see also Frings and Albery 2014). Assessing the processes of transitioning out of a high-dependency identity (see Herold and Søgaard 2019) may therefore also be a valuable tool to help explain the extent to which changes in group membership may facilitate or impede those transitioning out of high-control religions such as JW.

\section{Purpose of the present study}

In summary, and in conjunction with initial insights derived from qualitative research among former JWs and those in similar religions (Berger 2015; Lalich and McLaren 2010; Ransom et al. 2020 ; Testoni et al. 2019), there is a need to examine in larger populations the extent to which factors interact to shape the life chances of people leaving high-control religions. Further, by considering the theoretical insights regarding benefit of identity reformulation (Best et al. 2017; Jetten et al. 2017) and the stages/effects of ostracism and highlighting whether religious exit may vary as a function of exit method, commitment, and social support, the current research aimed to provide initial cross-sectional insights into the effects of longerterm religious ostracism in a real-world setting. 
The current study examined whether the extent to which former JWs have progressed in the reformulation of their identity impacts self-esteem and mental well-being in the face of religious shunning by former friends as well as family members. The following hypotheses were generated. First, we hypothesized that former members who experienced forced exit from the JW would experience more ostracism and greater deleterious effects on self-esteem and mental well-being than those who left voluntarily. Second, we hypothesized that heightened religious commitment during JW membership would be associated with more difficulty in establishing a post-religious sense of self and with adverse outcomes. Finally, we hypothesized that identification with social support groups would be associated with progress regarding identity reformulation and would benefit psychosocial outcomes.

\section{Method}

\section{Design}

A cross-sectional survey was utilized to investigate the effects of ostracism in individuals leaving the JW.

\section{Participants}

We recruited 554 (age 18-70, $\mathrm{M}=37.57, \mathrm{SD}=13.10 ; 62 \%$ female, $37 \%$ male, $1 \%$ other) ex-JWs, including 20 current JWs, using social media groups and snowball sampling. Participants received no monetary reimbursement for their participation. The original sample contained 890 participants. From this, 554 completed $80 \%$ or more of the questionnaire, which is considered necessary to provide robust and unbiased error estimates (Maas and Hox 2005). Of these 554, 121 were disfellowshipped (21.8\%), 95 disassociated (17.1\%), 315 faded (56.9\%), 20 claimed to still be JWs (3.6\%), and three did not disclose $(.5 \%)$ their membership status.

\section{Measures}

Pre-test questions included demographics (age, gender). The questionnaires administered were the Center for Epidemiologic Studies Depression Scale (CES-D; Radloff 1977), the Collective Self-Esteem Scale, consisting of four subscales; Membership self-esteem, Public collective self-esteem, Private collective self-esteem, and importance to identity (Luhtanen and Crocker 1992), and the Self-Esteem Scale (Dhingra 2013; Rosenberg 1965). Perceived ostracism was measured by an adapted Workplace Ostracism Scale (Ferris et al. 2008), and control was measured by the Perceived Behavioural Control Scale adapted from Fielding et al. (2008). Social support was measured using the Multidimensional Scale of Perceived Social Support (Zimet et al. 1988). Identity was measured using the Recovering Addict Identity Scale (Buckingham et al. 2013), adapted from (Doosje et al. 1995), and identity transition was measured using the Exeter Identity Transition Scale (EXITS; Haslam et al. 2008). Additional questions included ones related to length and method of JW membership, consequences of exit, and experiences of being a JW and leaving the JW. Participants were also given space to share their leaving stories if they wished to do so. 


\section{Procedure}

Following ethical approval from the university ethics board, participants were recruited via purposeful sampling through advertisements on various social media platforms such as Facebook and Reddit. Further participants were recruited through snowball sampling. Participants were recruited from December 2019-January 2020. All participants gave informed consent. After being briefed with the information sheet, participants provided their demographic details and then were given access to the full questionnaire, which was made available using a link to Qualtrics software, where the questionnaire had been designed.

\section{Results}

\section{Analytical procedure}

The data set was checked for univariate outliers, and pairwise plots were examined for any heteroscedasticity. Multivariate outliers were checked per Tabachnick and Fidell (2006), resulting in 72 participants being excluded. Variances for the dependent variables were adjusted so all were within a 10:1 ratio (Kline 2005). The final sample for analysis consisted of 482 participants $(M$ age $=37.26, S D$ age $=12.82)$, with 301 females.

Final variables were computed using SPSS Statistics software, and summary descriptive statistics are shown in Table 1.

An initial correlation matrix between the variables was then carried out using SPSS Statistics software. The summary is shown in Table 2.

For the ostracism scale, a negative correlation was shown between exit no choice and a positive correlation with commitment. A positive correlation was shown between commitment and identity transition and a negative correlation between commitment and self-esteem. A positive correlation was seen between membership collective self-esteem (CSE) and identity transition, and negative correlations were seen with self-esteem and CES-D scores. A negative correlation was seen between public CSE and CES-D scores. Importance of identity CSE was

Table 1 Final scale descriptives

\begin{tabular}{llll}
\hline Measure & M (SD) & Variance & Reliability $^{1}$ \\
\hline Recovering identity score & $19.50(3.93)$ & 15.45 & .75 \\
Identity transition score & $39.15(10.14)$ & 102.80 & .73 \\
Exit no choice & $1.78(.41)$ & .17 & .97 \\
Ostracism score & $47.33(19.69)$ & 387.66 & .93 \\
Self-Esteem score & $21.87(7.07$ & 49.94 & .95 \\
CES-D score & $21.10(15.40)$ & 237.00 & .78 \\
CSE membership scale & $20.28(5.12)$ & 26.21 & .78 \\
CSE private & $19.45(2.66)$ & 7.09 & .78 \\
CSE public & $20.63(4.23)$ & 17.86 & .66 \\
CSE importance to identity & $17.25(4.66)$ & 21.75 & 6.08 \\
Commitment & $7.63(2.47)$ & &
\end{tabular}

$C E S-D$, Center for Epidemiologic Studies Depression Scale; CSE, Collective Self-Esteem Scale.

${ }^{1}$ Split-half reliabilities 
Table 2 Correlation matrix between variables for final model

\begin{tabular}{|c|c|c|c|c|c|c|}
\hline & Ostracism & & $\begin{array}{l}\text { Membership } \\
\text { CSE }\end{array}$ & Commitment & $\begin{array}{l}\text { Importance to Identity } \\
\text { CSE }\end{array}$ & $\begin{array}{l}\text { Public } \\
\text { CSE }\end{array}$ \\
\hline Exit no choice & $-.34 * * *$ & & - & & & \\
\hline Commitment & $.13(.01)$ & & - & - & & \\
\hline Identity transition & - & & $.16^{* * * *}$ & $.18 * * *$ & $.15 * * *$ & \\
\hline Self-esteem & - & & $-.57 * * *$ & -.07 & $.21 * * *$ & - \\
\hline CES-D & - & & $-.44 * * *$ & - & $.16^{* * *}$ & $-.10(.01)$ \\
\hline Recovering identity & - & - & - & - & $.18 * * *$ & - \\
\hline
\end{tabular}

$* p<.05, * * p<.01, * * * p<.001$

$C E S-D$, Center for Epidemiologic Studies Depression Scale; CSE, Collective Self-Esteem Scale

positively correlated with CES-D score, self-esteem score, recovering identity score, and identity transition score.

\section{Main analyses}

Analyses were carried out using SPSS Amos 25. Path analysis aims to arrive at the most parsimonious model that explains the underlying data and does not significantly differ from it. Increasing the number of parameters in a model tends to improve fit but necessarily decreases parsimony. The best model optimizes fit and parsimony.

An initial model was created with the initial predictor as ostracism. Paths from ostracism were drawn to method of exit, commitment, social support, perceived behavioral control, whether individuals were JW from birth, how long since individuals had left the JW, and how many years since exiting the group. The final outcome variables were collective self-esteem (membership, public, private, and importance to identity), identity transition, identity recovery, self-esteem, and CES-D scores. Paths between all these variables were allowed to vary. The parameters for this initial model can be seen in Appendix A, Table 1.

Having examined the output and the parameters, those which were not a good fit to the data, with variables that were not significant or that had standardized values of less than .10, were removed. Removed paths were ostracism to social support, perceived behavioral control, JW from birth, and how many years since exiting. A new path was added from commitment to self-esteem, which yielded the final model. The parameters for the final model (see Tables 3 and 4) show that the final model fit was excellent $\left(\mathrm{X}^{2}(35)=43.67, p=.15\right)$.

The final model had ostracism as the initial predictor, with exit method, commitment level, and collective self-esteem as moderators. Collective self-esteem also acted as a predictor for the outcome variables, which were identity transition, recovering identity, self-esteem, and CES-D scores. In terms of variance the final model accounted for $10 \%$ of the variance of identity transition, $3 \%$ of recovering identity, $31 \%$ of self-esteem, and $24 \%$ of CES-D scores and is summarized in Fig. 1.

\section{Discussion}

The current study utilized a survey of purposively recruited former JWs to examine the extent to which a forced (as opposed to voluntary) exit would be associated with heightened 
Table 3 Parameter estimates for final model

\begin{tabular}{|c|c|c|}
\hline Path & $\begin{array}{l}\text { Unstandardized estimate (Standard } \\
\text { error) }\end{array}$ & $\begin{array}{l}\text { Standardized } \\
\text { estimate }\end{array}$ \\
\hline Ostracism Score $\rightarrow$ Exit No Choice 1 & $-.01(.00)$ & $-.34 * * *$ \\
\hline Ostracism Score $\rightarrow$ Commitment & $.02(.01)$ & $.13 * * *$ \\
\hline Commitment $\rightarrow$ Identity Transition & $.73(.17)$ & $.18^{* * * *}$ \\
\hline Commitment $\rightarrow$ Self-Esteem Score & $-.19(.09)$ & $-.07 * * *$ \\
\hline Membership CSE $\rightarrow$ CES-D Score & $-1.25(.13)$ & $-.44 * * *$ \\
\hline Membership CSE $\rightarrow$ Self-Esteem & $-.76(.05)$ & $-.57 * * *$ \\
\hline Membership CSE $\rightarrow$ Identity Transition & $.26(.09)$ & $.16^{* * * *}$ \\
\hline Importance to Identity CSE $\rightarrow$ CES-D Score & $.47(.13)$ & $.16^{* * * *}$ \\
\hline Importance to Identity CSE $\rightarrow$ Self-Esteem & $.30(.06)$ & $.21 * * *$ \\
\hline Importance to Identity $\rightarrow$ Identity Transition & $.35(.10)$ & $.15^{* * *}$ \\
\hline Public CSE $\rightarrow$ CES-D Score & $-.36(.15)$ & $-.10 * * *$ \\
\hline $\begin{array}{l}\text { Importance to Identity CSE } \rightarrow \text { Recovering } \\
\text { Identity }\end{array}$ & $.15(.04)$ & $.18^{* * *}$ \\
\hline Covariances & $\begin{array}{l}\text { Unstandardized Estimate (Standard } \\
\text { Error) }\end{array}$ & $\begin{array}{l}\text { Standardised } \\
\text { Estimate }\end{array}$ \\
\hline Membership CSE $\leftrightarrow$ Public CSE & $10.52(1.06)$ & $.51 * * *$ \\
\hline $\begin{array}{l}\text { Membership CSE } \leftrightarrow \text { Importance to Identity } \\
\text { CSE }\end{array}$ & $5.0(1.08)$ & $.21 * * *$ \\
\hline Public CSE $\leftrightarrow$ Importance to Identity CSE & $3.36(.88)$ & $.18^{* * * *}$ \\
\hline Private CSE $\leftrightarrow$ Membership CSE & $5.90(.63)$ & $.47 * * *$ \\
\hline Private CSE $\leftrightarrow$ Public CSE & $4.60(.51)$ & $.45^{* * * *}$ \\
\hline Self-Esteem Score $\leftrightarrow$ CESD Score & $35.80(3.75)$ & $.48 * * *$ \\
\hline Private CSE $\leftrightarrow$ Importance to Identity & $3.63(.54)$ & $.32 * * *$ \\
\hline Recovering Identity $\leftrightarrow$ CESD Score & $4.90(2.01)$ & $.10 * * *$ \\
\hline Variances & Estimate (Standard Error) & \\
\hline Ostracism Score & $383.10(24.70)^{* * *}$ & \\
\hline Exit No Choice & $.15(.01)^{* * *}$ & \\
\hline Commitment & $5.94(.38)^{* * *}$ & \\
\hline Membership CSE & $25.57(1.65)^{* * * *}$ & \\
\hline Public CSE & $16.94(1.10)^{* * *}$ & \\
\hline Importance to Identity CSE & $21.10(1.36)^{* * *}$ & \\
\hline Private CSE & $6.10(.39)^{* * *}$ & \\
\hline Self-Esteem Score & $32.83(2.12)^{* * *}$ & \\
\hline Identity Transition Score & $86.85(5.60)^{* * *}$ & \\
\hline Recovering Identity Score & $14.80(.95)^{* * *}$ & \\
\hline CES-D Score & $168.78(10.86)^{* * *}$ & \\
\hline \multicolumn{3}{|l|}{ Squared Multiple Correlations } \\
\hline Exit No Choice & .12 & \\
\hline Importance to Identity CSE & .00 & \\
\hline Public CSE & .00 & \\
\hline Membership CSE & .00 & \\
\hline Commitment & .02 & \\
\hline CES-D Score & .25 & \\
\hline Recovering Identity Score & .03 & \\
\hline Identity Transition Score & .10 & \\
\hline Self-Esteem Score & .31 & \\
\hline Private CSE & .00 & \\
\hline
\end{tabular}

$* p<.05, * * p<.01, * * * p<.001$. CES-D, Center for Epidemiologic Studies Depression Scale; CSE, Collective Self-Esteem Scale

experiences of ostracism and diminished psychosocial outcomes. We also sought to investigate the extent to which prior religious commitment and social identification following exit might worsen or mitigate any adverse impacts. First, we hypothesized that former members who were disfellowshipped (forced exit) from the JW would experience more ostracism and greater 
Table 4 Model fit parameters

\begin{tabular}{llllllllll}
\hline & CMIN & df & $p$ & NFI & CFI & AIC & RMSEA & Low & High \\
\hline Initial Model & 901.65 & 84 & $<.001$ & .40 & .39 & 1075.65 & .14 & .14 & .15 \\
Final Model & 43.67 & 35 & .15 & .96 & .99 & 105.67 & .02 & .00 & .04 \\
\hline
\end{tabular}

$C M I N$, chi-square value; $d f$, degrees of freedom; NFI, normed fit index; $C F I$, comparative fit index; AIC, Akaike information criterion; RMSEA, root mean square error of approximation

deleterious effects on self-esteem and mental well-being than those who left more voluntarily. Second, we posited that heightened religious commitment during JW membership would be associated with more difficulty in establishing a post-religious sense of self and adverse outcomes. Finally, we hypothesized that identification with other, supportive groups post exit would be associated with progress towards identity reformulation and would benefit psychosocial outcomes.

Beginning with a discussion of findings relating to type of exit and experiences of ostracism, findings were not in line with the hypothesis that JWs whose exit could be construed as forced would experience higher levels of ostracism. On the contrary, whereas shunning seemed to be a relatively widespread phenomenon among our respondents regardless of exit method, those who left voluntarily appeared to report more experiences of shunning and ostracism. Although existing research into leaving high-control religions consistently relates ostracism to leaving (Hookway and Habibis 2015; Lalich and McLaren 2010; Ransom et al. 2020; Testoni et al. 2019), it had not to date been examined whether type of exit might aggravate experiences thereof. We expected that being disfellowshipped would result in more ostracism because of mandated shunning, which could result in reduced 'control' according to Williams's (2009) model of ostracism that was derived primarily from experimental work

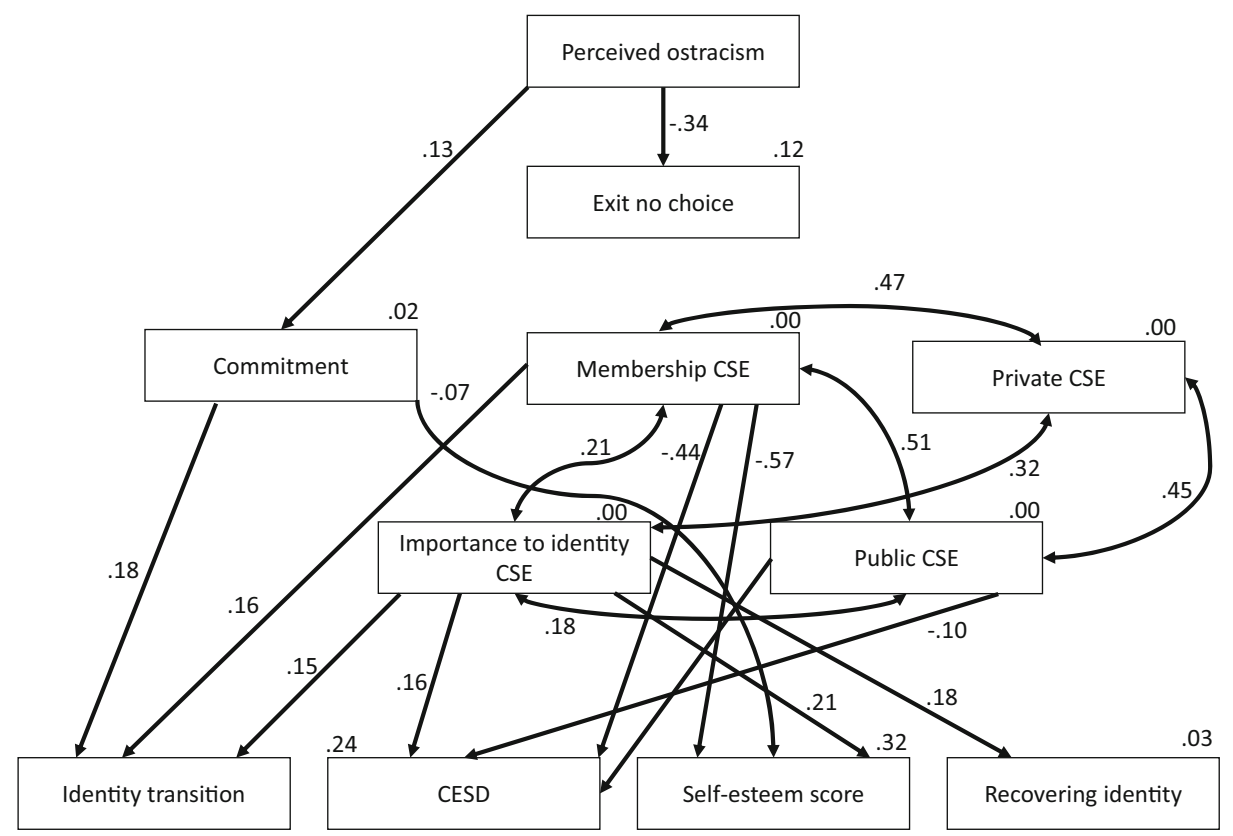

Fig. 1 Predictors and moderators 
indicating that a lack of perceived control is implicated in elevated experiences of ostracism (Hühnel et al. 2018; Williams and Jarvis 2006). Current findings, however, do not unequivocally support this notion in the real-world setting that was the focus of this study. This may be because being forced to leave the JW may not necessarily indicate a relative lack of control. It is also possible that this response pattern may, to some extent, reflect respondents' attempts to retrospectively make sense of their experiences in relation to their expectations. In other words, respondents who left voluntarily may not have expected to be subjected to the same degree of discipline (through mandated ostracism) as those who were forced to leave. As such, the possibly unanticipated outcome of experiencing more shunning than expected may have resulted in stronger perceived levels of ostracism. This is clearly speculative, and future research in this area is required.

In line with our second hypothesis, we found that higher respondent levels of commitment towards the JW during their membership in the religious organization were associated with increased ostracism post exit. Findings suggest that prior commitment levels moderated the extent to which ostracism was experienced. Specifically, it appeared that respondents who reported being relatively more devoted during their membership reported higher levels of ostracism. It was also found that higher commitment to the religion prior to leaving was associated with lower self-esteem post exit. These findings extend previous work that had already found that commitment levels can be an important predictor of motivations for exiting a religion (Bahr and Albrecht 1989; Fazzino 2014). Thus, the current study may provide an initial indication that motivations for exit, as a function of commitment, may shape post-exit paths. It is, for example, possible that individuals who are more committed to the JW religion in the first place benefit from religious membership to a greater degree and therefore have more to lose. Future research could examine this further and fruitfully ascertain the extent to which members of a religion with lower levels of commitment may, conversely, already have significant social support networks outside of the organization. While these findings may suggest that consideration of commitment and motivation for leaving might usefully help tailor support to those exiting high-control religions, other findings potentially paint a more nuanced picture.

In the context of considering our findings in relation to prior religious commitment impacting post-exit functioning, our unexpected finding that respondents with higher commitment levels during JW membership reported being more successful at transitioning their identity away from the religion is noteworthy. Although prior commitment appeared to be associated with higher levels of ostracism and diminished post-leaving self-esteem, as outlined, it also appeared to be linked with better outcomes regarding identity transition. This was not in line with our hypothesis that former highly committed members might remain "fused" (Swann et al. 2010, 2012) to their previous religious identity to a greater degree than those with lesser commitment. Previous smaller-scale qualitative work considering religious identity transition had provided some evidence that those who were more committed to the religion reported greater problems transitioning out of the JW and were what might be described as self-condemnatory (Lalich and McLaren 2010). Other research, however, has indicated that the exiting process can represent an emancipatory experience that helps to construct a perceptually more "authentic" identity (Testoni et al. 2019). Consideration of these somewhat discrepant findings in relation to the current findings may indicate that individual differences have a bearing on how people adjust their identity following a religious exit. Results may, for example, suggest that those more devoted to the religion may be better at commitment per se. 
In an initial assessment of the extent to which desistance models in other domains that are rooted in the social identity approach (Best et al. 2016; Kay and Monaghan 2019) may apply to religious exit, our study also examined the extent to which CSE would mitigate adverse effects of ostracism. Specifically, we expected that identification with social groups after exiting the JW would be associated with positive benefits. Our findings in this regard are complex and provide only partial support for the utility of applying this theoretical approach to understanding the religious exit process. In support of the model, findings indicate that membership CSE was positively correlated to identity transition/recovery and decreased self-reported dysphoria. Similarly, we found public CSE to be associated with decreased levels of dysphoria. Importance to identity CSE was further found to be positively associated with identity transition/recovery and self-esteem. These findings extend other recoveryfocussed work and theory (Beckwith et al. 2019; Best et al. 2016; Kay and Monaghan 2019) to a new domain and provide an initial indication that identity alignment with new supportive groups may help in the reformulation of identity that supports a post-exit lifestyle. As such, the current work aligns with, and possibly begins to bridge theoretically, previous findings indicating that religious exiters often experience, and respond to, losses of social support by seeking out new (online) groups to facilitate coping (Cheung and Lee 2010; Jacobs 1989; Nica 2019; Ridout et al. 2012; Smith 2011).

However, other findings were not consistent with the proposed model. Contrary to expectations, higher scores on the membership CSE Scale (i.e., the extent to which individuals value their contribution to a group) appeared to be associated with decreased self-esteem. It appears worthwhile to consider these unexpected findings in light of previous work indicating that one of the best predictors of self-esteem is the degree in which people perceive themselves as approved by the groups they are members of (Richman and Leary 2009). Seen in this light and considering that identity CSE (i.e., how important group membership is to the self-concept) was positively related to self-esteem, it is possible that different aspects of collective identification impact the construct independently and in different ways. In other words, although respondents may derive self-esteem from attaching importance to group membership, the perceived value of their contribution may harm self-perception, especially in relation to their former JW group identity conflicting with their current non-JW group identity, which could provoke feelings of guilt.

Similarly, the finding, in direct contrast with public CSE, that importance to identity CSE (i.e., the importance of group membership to self-concept) was associated with elevated subclinical depression levels may indicate that distinct aspects of social identification can exert differential effects on psychological outcomes. For example, it is conceivable that aspects of people's self-concept which would be considered "forbidden" and "apostate" by individuals previously important to respondents impact the identity reformulation process. Also, in light of consistent previous findings indicating that leaving JW impacts self-esteem and mental well-being adversely (Friedson 2015; Lalich and McLaren 2010; Ransom et al. 2020; Scheitle and Adamczyk 2010) and that, during their previous membership, an important source of self-esteem is derived from working towards fulfilling the organization's aims and goals (Holden 2002a; Hookway and Habibis 2015), more research is clearly required to understand fully how transitioning away from the religious organization interacts with distinct identity processes to shape perceptions of self-worth.

Several limitations need to be borne in mind when considering the findings. First, the crosssectional "snapshot" design prevents drawing conclusions regarding causality, and longitudinal inquiries in this area are urgently needed. Second, the purposive nature of the sampling methodology needs to be borne in mind as there is a possibility of sampling biases. Third, findings are also restricted by reliance on self-report data and the implications of this for shared method variance. 
In conclusion, a cross-sectional online survey of former JWs examined the extent to which experiences of ostracism and adverse well-being outcomes were impacted by method of leaving, prior commitment to the religion, and post-exit identification with other groups. In partial support of the social identity approach utilized previously in unrelated recovery/desistance research, results indicate that while some aspects of identification aid identity transition and enhance well-being, others may exert paradoxical effects. In view of possible implications for supporting individuals leaving high-control religions, future research in this area appears warranted to aid further development of an evidence-derived theoretical understanding of religious exit.

Supplementary Information The online version contains supplementary material available at https://doi.org/ 10.1007/s11089-020-00935-0.

Availability of data and materials The data and materials for this study are available on request.

Funding This research was funded by Edge Hill University through a graduate teaching assistant PhD scholarship.

\section{Compliance with ethical standards}

Conflict of interest The authors declare no conflicts of interest.

Open Access This article is licensed under a Creative Commons Attribution 4.0 International License, which permits use, sharing, adaptation, distribution and reproduction in any medium or format, as long as you give appropriate credit to the original author(s) and the source, provide a link to the Creative Commons licence, and indicate if changes were made. The images or other third party material in this article are included in the article's Creative Commons licence, unless indicated otherwise in a credit line to the material. If material is not included in the article's Creative Commons licence and your intended use is not permitted by statutory regulation or exceeds the permitted use, you will need to obtain permission directly from the copyright holder. To view a copy of this licence, visit http://creativecommons.org/licenses/by/4.0/.

\section{References}

Ai, A. L., Tice, T. N., Peterson, C., \& Huang, B. (2005). Prayers, spiritual support, and positive attitudes in coping with the September 11 national crisis. Journal of Personality, 73(3), 763-792. https://doi.org/10. $1111 /$ j.1467-6494.2005.00328.x.

Alcoholics Anonymous World Services. (2001). Alcoholics anonymous: The story of how many thousands of men and women have recovered from alcoholism (4th ed.). New York: Author.

Aydin, N., Fischer, P., \& Frey, D. (2010). Turning to God in the face of ostracism: Effects of social exclusion on religiousness. Personality and Social Psychology Bulletin, 36(6), 742-753. https://doi.org/10.1177/ 0146167210367491.

Bahr, H. M., \& Albrecht, S. L. (1989). Strangers once more: Patterns of disaffiliation from Mormonism. Journal for the Scientific Study of Religion, 28(2), 180-200. https://doi.org/10.2307/1387058.

Bar-Lev, M., \& Shaffir, W. (1997). Leaving religion and religious life. Greenwich: JAI Press.

Beckwith, M., Best, D., Savic, M., Haslam, C., Bathish, R., Dingle, G., Mackenzie, J., Staiger, P. K., \& Lubman, D. I. (2019). Social identity mapping in addiction recovery (SIM-AR): Extension and application of a visual method. Addiction Research \& Theory, 27(6), 462-471.

Berger, R. (2015). Challenges and coping strategies in leavening an ultra-orthodox community. Qualitative Social Work, 14(5), 670-686. https://doi.org/10.1177/1473325014565147.

Best, D., Beckwith, M., Haslam, C., Alexander Haslam, S., Jetten, J., Mawson, E., \& Lubman, D. I. (2016). Overcoming alcohol and other drug addiction as a process of social identity transition: The social identity 
model of recovery (SIMOR). Addiction Research \& Theory, 24(2), 111-123. https://doi.org/10.3109/ 16066359.2015.1075980.

Best, D., Irving, J., \& Albertson, K. (2017). Recovery and desistance: What the emerging recovery movement in the alcohol and drug area can learn from models of desistance from offending. Addiction Research \& Theory, 25(1), 1-10. https://doi.org/10.1080/16066359.2016.1185661.

Brown, R. (2020). The social identity approach: Appraising the tajfellian legacy. British Journal of Social Psychology, 59(1), 5-25. https://doi.org/10.1111/bjso.12349.

Buckingham, S. A., Frings, D., \& Albery, I. P. (2013). Group membership and social identity in addiction recovery. Psychology of Addictive Behaviors: Journal of the Society of Psychologists in Addictive Behaviors, 27(4), 1132-1140. https://doi.org/10.1037/a0032480.

Cheung, C. M. K., \& Lee, M. K. O. (2010). A theoretical model of intentional social action in online social networks. Decision Support Systems, 49(1), 24-30. https://doi.org/10.1016/j.dss.2009.12.006.

Davidman, L. (2014). Becoming un-orthodox: Stories of ex-Hasidic Jews. New York: Oxford University Press.

Davidman, L., \& Greil, A. L. (2007). Characters in search of a script: The exit narratives of formerly ultraorthodox Jews. Journal for the Scientific Study of Religion, 46(2), 201-216. https://doi.org/10.1111/j.14685906.2007.00351.x.

Dhingra, K. (2013). Validity and composite reliability of the Rosenberg self-esteem scale among UK university students. Journal of Humanistics and Social Sciences, 1(2), 24-30.

Doosje, B., Ellemers, N., \& Spears, R. (1995). Perceived intragroup variability as a function of group status and identification. Journal of Experimental Social Psychology, 31(5), 410-436. https://doi.org/10.1006/jesp. 1995.1018

Ebaugh, H. R. F. (1988). Becoming an ex: The process of role exit. Chicago: University of Chicago Press.

Faulkner, C. L. (2017). Identity change among ethno-religious border crossers: The case of the former Amish. Review of Religious Research, 59(4), 447-470. https://doi.org/10.1007/s13644-017-0309-2.

Fazzino, L. L. (2014). Leaving the church behind: Applying a deconversion perspective to evangelical exit narratives. Journal of Contemporary Religion, 29(2), 249-266. https://doi.org/10.1080/13537903.2014. 903664.

Ferris, D. L., Brown, D. J., Berry, J. W., \& Lian, H. (2008). The development and validation of the workplace ostracism scale. Journal of Applied Psychology, 93(6), 1348-1366. https://doi.org/10.1037/a0012743.

Fielding, K. S., McDonald, R., \& Louis, W. R. (2008). Theory of planned behaviour, identity and intentions to engage in environmental activism. Journal of Environmental Psychology, 28(4), 318-326. https://doi.org/10. 1016/j.jenvp.2008.03.003.

Friedson, M. L. (2015). Psychotherapy and the fundamentalist client: The aims and challenges of treating Jehovah's witnesses. Journal of Religion and Health, 54(2), 693-712. https://doi.org/10.1007/s10943-0149946-8.

Frings, D., \& Albery, I. (2014). The social identity model of cessation maintenance: Formulation and initial evidence. Addictive Behaviors, 44, 35-42. https://doi.org/10.1016/j.addbeh.2014.10.023.

Gebauer, J. E., Sedikides, C., \& Neberich, W. (2012). Religiosity, social self-esteem, and psychological adjustment: On the cross-cultural specificity of the psychological benefits of religiosity. Psychological Science, 23(2), 158-160. https://doi.org/10.1177/0956797611427045.

Gonsalkorale, K., \& Williams, K. D. (2007). The KKK won't let me play: Ostracism even by a despised outgroup hurts. European Journal of Social Psychology, 37(6), 1176-1186. https://doi.org/10.1002/ejsp. 392.

Gutgsell, J. (2017). 'A loving provision'? How former Jehovah's witnesses experience shunning practices, Unpublished master's thesis. Brussels, Belgium: Vrije Universiteit Brussel.

Hartgerink, C. H. J., van Beest, I., Wicherts, J. M., \& Williams, K. D. (2015). The ordinal effects of ostracism: A meta-analysis of 120 cyberball studies. PLoS One, 10(5), e0127002. https://doi.org/10.1371/journal.pone. 0127002 .

Haslam, C., Holme, A., Haslam, S. A., Iyer, A., Jetten, J., \& Williams, W. H. (2008). Maintaining group memberships: Social identity continuity predicts well-being after stroke. Neuropsychological Rehabilitation, 18(5-6), 671-691. https://doi.org/10.1080/09602010701643449.

Haslam, C., Jetten, J., \& Alexander, S. H. (2011). The social cure: Identity, health and well-being. Hove, UK: Psychology Press.

Herold, M. D., \& Søgaard, T. F. (2019). Disturbing the 'spoiled-unspoiled' binary: Performances of recovering identities in drug-experienced youths' friendship narratives. Addiction Research \& Theory, 27(3), 226-234. https://doi.org/10.1080/16066359.2018.1493462.

Holden, A. (2002a). Cavorting with the devil: Jehovah's witnesses who abandon their faith. Leicester University, Leicester, England: Unpublished manuscript http:/www.lancaster.ac.uk/fass/sociology/papers/holdencavorting-with-the-devil-pdf.

Holden, A. (2002b). Jehovah's witnesses: Portrait of a contemporary religious movement. London: Routledge. 
Hookway, N. S., \& Habibis, D. (2015). 'Losing my religion': Managing identity in a post-Jehovah's witness world. Journal of Sociology, 51(4), 843-856.

Hühnel, I., Kuszynski, J., Asendorpf, J. B., \& Hess, U. (2018). Emotional mimicry of older adults' expressions: Effects of partial inclusion in a cyberball paradigm. Cognition and Emotion, 32(1), 92-101. https://doi.org/ 10.1080/02699931.2017.1284046.

Iannaccone, L. R. (1994). Why strict churches are strong. American Journal of Sociology, 99(5), 1180-1211. https://doi.org/10.1086/230409.

Itzhaki, Y., Yablon, Y. B., \& Itzhaky, H. (2020). Becoming less religious (BLR) and well-being among high school dropouts. Psychology of Religion and Spirituality, 12(1), 45-54. https://doi.org/10.1037/rel0000179.

Jackson, B. R., \& Bergeman, C. S. (2011). How does religiosity enhance well-being? The role of perceived control. Psychology of Religion and Spirituality, 3(2), 149-161. https://doi.org/10.1037/a0021597.

Jacobs, J. L. (1989). Divine disenchantment: Deconverting from new religions. Bloomington: Indiana University Press.

Jamieson, A. (2002). A churchless faith: Faith journeys beyond the churches. London: SPCK.

Jetten, J., Haslam, S. A., Cruwys, T., Greenaway, K. H., Haslam, C., \& Steffens, N. K. (2017). Advancing the social identity approach to health and well-being: Progressing the social cure research agenda-Applying the social cure. European Journal of Social Psychology, 47(7), 789-802. https://doi.org/10.1002/ejsp.2333.

Joseph, L. J., Joseph, L. J., \& Cranney, S. (2017). Self-esteem among lesbian, gay, bisexual and same-sexattracted Mormons and ex-Mormons. Mental Health, Religion \& Culture, 20(10), 1028-1041. https://doi.org/ $10.1080 / 13674676.2018 .1435634$.

Kay, C., \& Monaghan, M. (2019). Rethinking recovery and desistance processes: Developing a social identity model of transition. Addiction Research \& Theory, 27(1), 47-54. https://doi.org/10.1080/16066359.2018. 1539479.

Kline, R. B. (2005). Principles and practice of structural equation modeling (2nd ed.). New York: The Guilford Press.

Kelly, J. F. (2017). Is alcoholics anonymous religious, spiritual, neither? Findings from 25 years of mechanisms of behavior change research. Addiction, 112(6), 929-936. https://doi.org/10.1111/add.13590.

Kelly, J. F., \& Eddie, D. (2020). The role of spirituality and religiousness in aiding recovery from alcohol and other drug problems: An investigation in a national U.S. sample. Psychology of Religion and Spirituality, 12(1), 116-123. https://doi.org/10.1037/rel0000295.

Khalil, M. H., \& Bilici, M. (2007). Conversion out of Islam: A study of conversion narratives of former Muslims. The Muslim World, 97(1), 111-124. https://doi.org/10.1111/j.1478-1913.2007.00161.x.

Lalich, J., \& McLaren, K. (2010). Inside and outcast: Multifaceted stigma and redemption in the lives of gay and lesbian Jehovah's witnesses. Journal of Homosexuality, 57(10), 1303-1333. https://doi.org/10.1080/ 00918369.2010.517076.

Levine, M., Cassidy, C., Brazier, G., \& Reicher, S. (2002). Self-categorization and bystander non-intervention: Two experimental studies. Journal of Applied Social Psychology, 32(7), 1452-1463. https://doi.org/10. 1111/j.1559-1816.2002.tb01446.x.

Luhtanen, R., \& Crocker, J. (1992). A collective self-esteem scale: Self-evaluation of one's social identity. Personality and Social Psychology Bulletin, 18(3), 302-318. https://doi.org/10.1177/0146167292183006.

Maas, C. J., \& Hox, J. J. (2005). Sufficient sample sizes for multilevel modeling. Methodology, 1(3), 86-92.

McIntosh, D. N., Silver, R. C., \& Wortman, C. B. (1993). Religion's role in adjustment to a negative life event: Coping with the loss of a child. Journal of Personality and Social Psychology, 65(4), 812-821. https://oi. org/10.1037/0022-3514.65.4.812.

Miller, J. K. (1988). Damned if you do, damned if you don't: Religious shunning and the free exercise clause. University of Pennsylvania Law Review, 137(1), 271-302. https://doi.org/10.2307/3312170.

Nica, A. (2019). Exiters of religious fundamentalism: Reconstruction of social support and relationships related to well-being. Mental Health, Religion \& Culture, 22(5), 543-556. https://doi.org/10.1080/13674676.2019. 1636015.

Pargament, K. I., Koenig, H. G., \& Perez, L. M. (2000). The many methods of religious coping: Development and initial validation of the RCOPE. Journal of Clinical Psychology, 56(4), 519-543. https://doi.org/10. 1002/(sici)1097-4679(200004)56:4<519::aid-jclp6>3.0.co;2-1.

Park, C. L., Holt, C. L., Le, D., Christie, J., \& Williams, B. R. (2018). Positive and negative religious coping styles as prospective predictors of well-being in African Americans. Psychology of Religion and Spirituality, 10(4), 318-326. https://doi.org/10.1037/rel0000124.

Radloff, L. S. (1977). The CES-D scale: A self-report depression scale for research in the general population. Applied Psychological Measurement, 1(3), 385-401. https://doi.org/10.1177/014662167700100306.

Ransom, H.J., Monk, R.L., \& Heim, D. (2020) Grieving the living: The Social Death of former Jehovah's Witnesses. Journal of religion and health. (in press) 
Ren, D., Wesselmann, E. D., \& Williams, K. D. (2018). Hurt people hurt people: Ostracism and aggression. Current Opinion in Psychology, 19, 34-38. https://doi.org/10.1016/j.copsyc.2017.03.026.

Richman, L. S., \& Leary, M. R. (2009). Reactions to discrimination, stigmatization, ostracism, and other forms of interpersonal rejection: A multimotive model. Psychological Review, 116(2), 365-383. https://doi.org/10. $1037 / \mathrm{a} 0015250$.

Ridout, B., Campbell, A., \& Ellis, L. (2012). 'Off your face(book)': Alcohol in online social identity construction and its relation to problem drinking in university students. Drug and Alcohol Review, 31(1), 20-26. https:// doi.org/10.1111/j.1465-3362.2010.00277.x.

Rosenberg, M. (1965). Society and the adolescent self-image. Princeton, NJ: Princeton University Press.

Scheitle, C. P., \& Adamczyk, A. (2010). High-cost religion, religious switching, and health. Los Angeles: Sage., 51, 325-342. https://doi.org/10.1177/0022146510378236.

Sherman, A. C., Plante, T. G., Simonton, S., Latif, U., \& Anaissie, E. J. (2009). Prospective study of religious coping among patients undergoing autologous stem cell transplantation. Journal of Behavioral Medicine, 32(1), 118-128. https://doi.org/10.1007/s10865-008-9179-y.

Smith, J. M. (2011). Becoming an atheist in America: Constructing identity and meaning from the rejection of theism. Sociology of Religion, 72(2), 215-237. https://doi.org/10.1093/socrel/srq082.

Stark, R., \& Iannaccone, L. R. (1997). Why the Jehovah's witnesses grow so rapidly: A theoretical application. Journal of Contemporary Religion, 12(2), 133-157. https://doi.org/10.1080/13537909708580796.

Streib, H., Hood, R. W., Keller, B., Csöff, R. M., \& Silver, C. F. (2009). Deconversion: Qualitative and quantitative results from cross-cultural research in Germany and the United States of America (Vol. 5). Gottingen, Germany: Vandenhoeck \& Ruprecht.

Swann, W. B., Gomez, A., Huici, C., Morales, J. F., \& Hixon, J. G. (2010). Identity fusion and self-sacrifice: Arousal as a catalyst of pro-group fighting, dying, and helping behavior. Journal of Personality and Social Psychology, 99(5), 824-841. https://doi.org/10.1037/a0020014.

Swann, W. B., Jetten, J., Gomez, A., Whitehouse, H., \& Bastian, B. (2012). When group membership gets personal: A theory of identity fusion. Psychological Review, 119(3), 441-456. https://doi.org/10.1037/a0028589.

Tabachnick, B. G., \& Fidell, L. S. (2006). Using multivariate statistics (5th ed.). London: Allyn and Bacon.

Tajfel, H. (1978). Differentiation between social groups: Studies in the social psychology of intergroup relations. London: Academic Press.

Tajfel, H., \& Turner, J. C. (1979). An integrative theory of intergroup conflict. In M. J. Hatch \& M. Schultz (Eds.), Organizational identity: A reader (pp. 56-65). Oxford: Oxford University Press.

Testoni, I., Bingaman, K., Gengarelli, G., Capriati, M., De Vincenzo, C., Toniolo, A., \& Zamperini, A. (2019). Self-appropriation between social mourning and individuation: A qualitative study on psychosocial transition among Jehovah's witnesses. Pastoral Psychology, 68, 687-703. https://doi.org/10.1007/s11089-01900871-8.

Tonigan, J. S., Rynes, K. N., \& McCrady, B. S. (2013). Spirituality as a change mechanism in 12-step programs: A replication, extension, and refinement. Substance Use and Misuse, 48(12), 1161-1173. https://doi.org/10. 3109/10826084.2013.808540.

Turner, J. C., \& Hogg, M. (1987). Rediscovering the social group: A self-categorization theory. British Journal of Social Psychology, 26(4), 347-348.

van Beest, I., \& Williams, K. D. (2006). When inclusion costs and ostracism pays, ostracism still hurts. Journal of Personality and Social Psychology, 91(5), 918-928. https://doi.org/10.1037/0022-3514.91.5.918.

Wallis, R. (1984). The elementary forms of the new religious life. London: Routledge \& Kegan Paul.

Wesselmann, E. D., \& Williams, K. D. (2017). Social life and social death: Inclusion, ostracism, and rejection in groups. Group Processes and Intergroup Relations, 20(5), 693-706. https://doi.org/10.1177/ 1368430217708861.

Wesselmann, E. D., Nairne, J. S., \& Williams, K. D. (2012). An evolutionary social psychological approach to studying the effects of ostracism. Journal of Social, Evolutionary and Cultural Psychology, 6(3), 309-328. https://doi.org/10.1037/h0099249.

Williams, K. D. (2008). Ostracism: Effects of being ignored and excluded. International Journal of Psychology, 43(3-4), 398-399.

Williams, K. D. (2009). Chapter 6 Ostracism. In Ostracism: A temporal need-threat model (pp. 275-314). San Diego, CA: Elsevier Academic Press. https://doi.org/10.1016/S0065-2601(08)00406-1.

Williams, K. D., \& Jarvis, B. (2006). Cyberball: A program for use in research on interpersonal ostracism and acceptance. Behavior Research Methods, 38(1), 174-180. https://doi.org/10.3758/BF03192765.

Wilson, B. R., \& Cresswell, J. (Eds.). (1999). New religious movements: Challenge and response. London: Routledge. https://doi.org/10.4324/9780203129166.

Zadro, L., \& Williams, K. D. (2006). How do you teach the power of ostracism? Evaluating the train ride demonstration. Social Influence, 1(1), 81-104. https://doi.org/10.1080/15534510500400669. 
Zimet, G. D., Dahlem, N. W., Zimet, S. G., \& Farley, G. K. (1988). The multidimensional scale of perceived social support. Journal of Personality Assessment, 52(1), 30-41. https://doi.org/10.1207/ s15327752jpa5201_2.

Publisher's Note Springer Nature remains neutral with regard to jurisdictional claims in published maps and institutional affiliations. 